\title{
INTERSEÇÕES ENTRE CULTURA, ARTE E POLÍTICA NA "BOEMIA" DE FORTALEZA NO CONTEXTO DITATORIAL
}

\section{Daniele Costa da Silva ${ }^{1}$}

\begin{abstract}
Resumo: O foco do artigo são as práticas, ambientes e sociabilidades de um estilo de vida urbano associado ao termo "boemia", na cidade de Fortaleza entre décadas de 1960 e 1970, quando grupos artísticos, políticos e intelectualizados delineiam movimentos no espaço público da cidade, compondo trajetórias, identidades e memórias num tempo-espaço demarcado pelo contexto ditatorial. A "boemia", nesse sentido, é utilizada por esses grupos para definir suas práticas e vivências no espaço urbano, sob o contexto repressor vivido no país. São personagens que ensaiam, em suas deambulações, um estilo de vida, atuando com uma gramática de sentidos e ações, ao tempo em que forjam ideias, comportamentos e práticas de uma nova cultura urbana numa cidade que principiava a aspirar ares metropolitanos. O texto é resultado da tese de doutoramento em sociologia, concluída em 2012, que abordou esse estilo de vida na cidade de Fortaleza, entre os anos 1960 e 1970. A pesquisa baseou-se em doze entrevistas com alguns atores sociais participantes desse contexto, bem como levantamento em jornais, livros, músicas e documentos do contexto em análise.
\end{abstract}

Palavras-chave: Cidade. Boemia. Sociabilidade. Estilo de vida. Ditadura

\section{SOBRE CIDADES E VEREDAS}

Nos percalços dos estudos urbanos, ou melhor, nos estudos realizados na/ sobre a cidade muitas veredas se abrem ao pesquisador. A cada caminho trilhado um mundo se revela, com cores, sons e atores sociais distintos. Assim são as cidades, diversas, inquietantes. Lugares e modos de vida que afugentam e provocam medo e repulsa, ao tempo em que exercem um poder de atração (BAUMAN, 2005; MAGNANI, 1996; SIMMEL, 2001). Revelam faces obscuras e cruéis, cravadas na violência, na indiferença, em especial as faces da segregação social e da "abstenção" ou a atitude deliberada de evitação do encontro com o outro (LEITE, 2009). Ao longo de anos, as cidades proporcionaram e proporcionam espaços e

1 Professora Adjunta do Curso de Ciências Sociais da Universidade Estadual Vale do Acaraú - UEVA. E-mail: danileta@gmail.com 
oportunidades de encontros e desencontros, dores e prazeres, no burburinho de suas ruas, nos seus modos de viver.

Fortaleza, como outras grandes cidades, também se desnuda de formas várias de acordo com a vereda escolhida para adentrar suas tramas. Nossa busca, neste texto, nos remete à cidade em vias de metropolização, quando, nos idos das décadas de 1960 e 1970, suas feições, modos e estilos de vida ganham expressões de novos tempos, marcados por comportamentos que indicavam mudanças, num contexto de forte repressão e censura impostas pela experiência de uma ditadura, estreita em pensamentos e violenta nas ações. Não apenas a cidade se metamorfoseava, ganhava outros contornos, alargava-se em número de bairros e moradores, como se fazia notar um jeito "moderno" de lidar com seus espaços, sob as influências de movimentos contraculturais que ocorriam em outros cantos do mundo.

A trilha que aqui seguimos é a da chamada "boemia", tema curioso, inquietante e que ganha contornos distintos ao longo da história e nos muitos espaços nos quais se assenta. Nos estudos e pesquisas sobre o tema (SEIGEL, 1992; DARNTON, 1987; BOURDIEU, 1996; PAIS, 2003; RAGO, 1997; CHALHOUB, 2001; MATOS, 1996), a boemia não se apresenta como um conceito, mas como uma gama de experiências e atores em diferentes tempos e lugares. Segundo Rafael (2010, p. 02)

[...] as tentativas de definição da boemia e dos boêmios ${ }^{2}$ são, ao mesmo tempo, complexas e frustrantes, em primeiro lugar porque aquilo que muitas vezes se utiliza para adjetivar essa prática diz respeito a uma gama variada de atitudes e modos de vida que envolvem grupos, comunidades e indivíduos que nada guardam de semelhante entre si. Em segundo lugar, porque tais definições são tanto contraditórias quanto defendidas com grande paixão. Contudo, fazendo uso do que escreveu o poeta beat, Kenneth Rexroth, segundo o qual "não havia Baudelaire na Babilônia”, Wilson afirma que as condições que possibilitaram o aparecimento do boêmio só se apresentaram na França do Segundo Império, quando se instaurou essa "subcultura identificável".

Nesta abordagem, boemia é uma categoria nativa que designou um estilo de vida urbano na cidade de Fortaleza. Esse estilo de vida associa-se às práticas

2 Bohémien era a palavra francesa que descrevia o submundo de Paris. O termo origina-se da designação atribuída pelos franceses aos ciganos, cuja procedência acreditava-se ser da região da Boêmia, atual República Tcheca, na Europa Central. Os ciganos costumavam seguir uma vida considerada peregrina, nômade, incerta, errante, daí serem associados ao comportamento de determinados indivíduos que, em geral, não condiziam com os padrões "sérios" de conduta social (Leitão, 2000, p. 55). 
sociais contestatórias, à temática política, ao universo artístico e cultural da cidade e aos bares e foi objeto de estudo de nossa tese de doutorado ${ }^{3}$ (SILVA, 2012). Nela buscamos compreender como personagens pertencentes a uma classe média intelectualizada, participantes de movimentos culturais (música, artes plásticas, cinema, etc), de atividades profissionais (jornalismo, arquitetura, direito), ou atividades políticas encontraram-se nos espaços públicos da cidade, em especial nos bares, e integraram um dado estilo de vida na cidade de Fortaleza dos anos 1960 e 1970.

Conforme nossos interlocutores, a boemia está relacionada a uma conjunção de fatores: 1 . ao processo de expansão da cidade, que alargou a sua malha urbana e os espaços de encontro e lazer, mantendo, contudo, a possibilidade de relações primárias; 2 . à emergência de uma classe média urbana intelectualizada, desejosa por descobertas e ampliação dos horizontes; 3. às transformações que o período e suas personagens vivenciaram no tocante aos comportamentos, ideologias e movimentos de contracultura, promovendo a formação de narrativas identitárias marcadas por um caráter contestador e crítico; 4 à efervescência política, cultural e artística que se dava no Brasil, associada às formas de reação política, lúdicas e culturais à dinâmica de um contexto repressor imposto pelo regime militar e o desejo de liberdade, de quebra de convenções e de refúgio que a ele se vincula.

A pesquisa contou com a realização de entrevistas com personagens que nos chegaram a partir de nossa frequência em alguns bares da cidade de Fortaleza, da leitura de jornais e estudos com foco nos anos 1960 e 1970. Foram elas que teceram um fio condutor de outras tantas personagens, baseado no método da "bola de neve" (BIERNACKI \& WALDORF, 1981; BALDIN \& MUNHOZ, 2011), que consiste na construção qualitativa de uma amostra significativa, na qual os sujeitos indicam outros considerados relevantes, até que as informações apontem para uma saturação dos dados, garantindo fidedignidade à pesquisa. Dessa forma, foram entrevistadas doze pessoas (três cantores/compositores, uma cantora, uma funcionária pública, um cineasta/advogado, um cronista/poeta, um músico, um artista plástico e três professores universitários). As entrevistas, gravadas, ocorreram entre 2009 e 2011, nos locais indicados por meus interlocutores, sendo assim espacialmente distribuídas: três em suas residências, três em seus escritórios, cinco nos bares que ainda frequentam em Fortaleza (Flórida Bar, Alpendre Produtos da Fazenda e Bar do Papai) e uma no Ideal Clube.

Adotamos, entretanto, outras estratégias de pesquisa. Falamos em estraté- 
gias metodológicas por entendermos que a metodologia se constrói por recursos utilizados pelo pesquisador para melhor se aproximar, observar, conhecer e analisar seu "objeto". Cria-se estratégias como formas de agir e pensar. Destarte, realizamos pesquisa na sede do Jornal O Povo, bem como na Biblioteca Pública Governador Menezes Pimentel. Os arquivos do jornal auxiliam na confirmação de dados, além de enriquecerem o texto com informações pertinentes a respeito não apenas do contexto urbano e histórico, como também sobre os discursos construídos a respeito da boemia. Utilizamos os dois jornais de maior circulação no estado do Ceará, O Povo e Diário do Nordeste.

Dedicamos, ainda, um tempo para buscar vídeos, discos, filmes e músicas que falassem sobre o período que adotamos como recorte temporal a ser analisado, mormente as músicas que compuseram o disco o "Pessoal do Ceará" ${ }^{\text {(PI- }}$ MENTEL, 2002; ROGÉRIO, 2008). Visitamos sítios virtuais, bem como redes sociais, de forma a observar redes de amizade, eventos e publicações que nos possibilitassem "pontes" com o contexto e as personagens da pesquisa. Dessa forma, pudemos localizar pessoas cuja residência não é mais Fortaleza, como Ieda Estergilda, poetisa e compositora, que atualmente reside em São Paulo e que nos enviou um belo relato de sua experiência no Bar do Anísio, um dos lugares de grande relevância para o nosso estudo.

$\mathrm{Na}$ trilha escolhida retratamos uma cidade em transição. A metropolização se inicia, mas sem eliminar de todo as marcas de provincianismo em alguns de seus costumes e comportamentos, e tem como personagens centrais os atores sociais que participaram intensamente dos universos culturais, artísticos, intelectuais e políticos da época. Foram esses os nossos interlocutores privilegiados, que entre os anos 1960 e 1970 eram jovens estudantes universitários, militantes e intelectuais de esquerda, músicos, cantores, compositores, artistas plásticos e poetas, que forjaram, a seu modo, uma vivência por eles denominada "boêmia", na cidade de Fortaleza. Sobre essa relação entre cidade e "boemia" centra-se nossa discussão nesse texto, cuja leitura servirá de pretexto para a discussão dos modos e estilos de vida característicos das cidades, sobretudo quando o tempo é a noite, o espaço as ruas e os bares.

Aquilo que em Fortaleza foi denominado por meus informantes de "boemia" não foi, contudo, um fenômeno específico ou isolado, tampouco exclusivo à realidade de Fortaleza, mas a expressão local de um processo mais amplo que ocorreu em todo o país, sem necessariamente adotar a "boemia" como categoria

4 Pessoal do Ceará" foi um movimento cultural formado por artistas cearenses que obteve grande repercussão no país, sobretudo na música, quando do lançamento do disco "Meu Corpo Minha Embalagem todo Gasto na Viagem" - Pessoal do Ceará", em 1972. 
de referência, como atestam os estudos de Marques (2005) sobre a cidade do Crato/Ce, Madureira (1996) sobre o Recife/PE e Musse (2006) acerca de Juiz de Fora/Mg. Na verdade, penso se tratar de uma rica experiência urbana brasileira, quando os espaços públicos de discussão são alimentados pela necessidade não apenas do debate sobre a realidade do país, mas da produção cultural e da mobilização política, dando conta de novos imaginário e cultura urbanos, opostos à censura e à repressão ditatoriais.

O período em foco marca a proliferação de fóruns de discussão e debate nos espaços públicos que resistiram ao silenciamento provocado pela rigidez ditatorial, especialmente os bares. Podemos pensá-los como uma esfera pública, usando aqui a discussão habermasiana (HABERMAS, 1990). Sob a ótica do autor, a esfera pública burguesa se ergue não como mero espaço público (praça, rua), nem equivale ao Estado. Associa-se aos debates, à circulação de ideias, informações, encontros entre pessoas que discutem pontos de vista e que passam também a compor uma opinião pública. Marcados por uma sociabilidade típica, nos quais o "jogar conversa fora" ganha proeminência, nos bares há uma forte presença de grupos bem informados e que formavam uma opinião acerca da cidade, do país e da conjuntura vivida.

\section{FORTALEZA - EXPANSÃO URBANA, CONTRACULTURA E O CONTEXTO DITATORIAL}

Fortaleza é hoje a $5^{\text {a }}$ capital brasileira em número de habitantes. Segundo dados do IBGE $^{5}$ a cidade concentra 2.643.247 habitantes, que vivenciam as agruras e as oportunidades que o viver numa grande cidade proporciona. Entretanto, o cenário do presente estudo contempla uma cidade ainda em expansão. À década de 1970, a capital cearense se constituía de 842.702 habitantes e suas principais atividades econômicas e espaços de lazer concentravam-se no centro. Os ares da modernidade já sopravam desde o Século XIX, porém novos ventos traziam notícias e dilemas do processo de metropolização em curso, com mudanças nos comportamentos sob a onda contracultural dos anos 1960 que se espraiava e chegava não apenas a Fortaleza, mas a cidades menores, como o Crato, no interior do Ceará (MARQUES, 2005).

Uma onda de contracultura se espalhou pelo Ocidente, deixando atordoados os mais refratários às mudanças. Da Europa, chegavam os ventos de um período de contestação que ficou conhecido como Maio de 68, ocorrido na França. Os

5 Instituto Brasileiro de Geografia e Estatística - Estimativa da População Brasileira, 2018 
jovens saíam às ruas e gritavam palavras de ordem, do tipo: "é proibido proibir" ou "sejam realistas, exijam o impossível". Emergiram novas experiências no campo da música e das artes, como o Festival de Woodstok, em 1969, nos Estados Unidos. O pacifismo ganhou peso com os protestos contra a Guerra do Vietnã (1959-1975), também naquele país. Os cinemas europeu e americano divulgavam comportamentos, ideologias e compreensões estéticas, tais como o existencialismo, o realismo, o feminismo, espalhando jeitos novos de ver o mundo, de compreender a vida, o amor, o sexo. Da Inglaterra chegava um som diferente, Os Beatles. O Rock ganha força com posturas de crítica ao sistema capitalista e define estilos de vida na cidade. Os hippies chegam em grupos às cidades e espantam os menos avisados.

Esses movimentos e processos tornam mais agitada a conjuntura brasileira, marcada por um caleidoscópio de acontecimentos - movimentos no campo pela reforma agrária, formação da classe média, processo de urbanização crescente. No campo da cultura, os Centros Populares de Cultura - CPCs; a Bossa Nova, que já vinha desde os anos 1950; a Jovem Guarda, o Cinema Novo e sua estética rebuscada; a ebulição da Música Popular Brasileira (MPB), "sem os arroubos de opereta de Vicente Celestino" (CASTRO, 2008, p.23,). Na Bahia, o Tropicalismo unia o tradicional ao moderno, com sons de guitarra e músicas de Vicente Celestino, causando espanto nas apresentações durante os festivais de música. Em Minas Gerais, explode o Clube da Esquina, com seus sons intimistas, com caras e cores do interior do Brasil, mas com temáticas de juventude, de amor. No Ceará começa a ser forjar também um grupo que ficou conhecido como o Pessoal do Ceará e que tem, para os interesses deste trabalho, um papel fundamental.

Esse contexto de mudanças nos comportamentos ocorre, no caso de Fortaleza, numa cidade em crescimento, sobretudo em função dos movimentos migratórios originados nos municípios do sertão. Não apenas se observa o crescimento desordenado da cidade, expandindo-a para as franjas da pobreza e da favelização, mas a emergência de uma classe média intelectualizada, cujo ingresso na universidade potencializa encontros e sociabilidades públicas, nas ruas, nos bares, aqui entendidos em sentido amplo, ou seja, como espaço público, ainda que se percebam práticas tipicamente ligadas ao universo privado. Afinal, os espaços são híbridos, diria Canclini (2008). Não existem como substâncias puras ou impermeáveis.

A cidade observa a formação de rodas e "rondas boêmias" que se espalham por seu tecido e a expandem numa flanerie um tanto quanto híbrida - outsider, mas nem tanto, haja vista compromissos com o mundo do trabalho, da univer- 
sidade e da família. Nessas rodas a "arte de narrar", de contar histórias ganha em importância, sob colorações de uma sociabilidade lúdica, irreverente, de jovens boêmios que descobriam espaços, lugares e cantos novos. Esse é um tempo em que as informações vinham das conversas, do rádio, dos livros, dos cinemas, das canções. Tempos diferentes dos atuais, quando estamos a um clique de bibliotecas, museus e livros de todo o mundo via meios eletrônicos.

Podemos pensar que esses aspectos não configuram novidade, haja vista as mudanças que, em geral, os jovens experimentam ao se inserirem no universo acadêmico. Contudo, desde os anos 1960 metamorfoseiam-se as formas de compreender o mundo e a vida e a necessidade de experimentação parece ganhar força. Falamos aqui de uma geração que por anos tornou-se objeto de inúmeros estudos, a geração dos anos 1960, associada a valores de transgressão, rebeldia e mudança. Não significa tomá-la como um absoluto ou um agrupamento homogêneo. Tampouco, implica uma apologia ao passado de uma suposta "geração diferente", mas uma referência necessária para compreendermos o que há novo e quais implicações recaem sobre as práticas e referentes da "boemia".

Contudo, o período ditatorial brasileiro, sobretudo em sua face mais implacável, no final de 1968, com a decretação do Ato Institucional Nº5, impôs limites a essa efervescência cultural, artística e política. O medo de morrer, de ser preso, torturado ou exilado teve como contraponto expressões apaixonadas de resistência, a necessidade de criar coisas inovadoras e diferentes, o apego à cultura local, imbricado com influências que vinham de fora, dando margem não apenas a comportamentos contestadores, mas à manifestações culturais vanguardistas.

Opiniões divididas e radicalização política compõem o período. Leituras, discussões, emergência de novos grupos, novas turmas se consolidam e buscam espaços de encontro menos convencionais. Nesse contexto, os bares ${ }^{6}$ assumem importância como lugares agregadores, pontos de encontro, marcados por certa liminaridade e pela heterogeneidade de pessoas, ainda que as marcações sociais não deixem de existir. Com o silenciamento de partidos políticos, sindicatos, associações e demais canais de participação política, os bares e espaços de lazer assumem um papel relevante como ponto de encontro e de discussão de pessoas que se identificavam por sua oposição à repressão, atuando como uma "válvula de escape", na expressão utilizada por um de meus interlocutores.

São anos em que o mundo parece crescer e transcender as fronteiras dos

6 E são os bares espaços por excelência do que se passou a chamar "boemia". Desperta interesse as representações sociais acerca desses lugares em princípios dos anos 1970. Em pesquisa nos jornais locais, as primeiras referências a bares ou à noite concentram-se no noticiário policial, quando da ocorrência de brigas e discussões nos bares e prostíbulos situados, especialmente, no centro da cidade. 
quintais das residências, dos limites dos bairros e provocar a necessidade de conhecer, de encontrar pessoas. Das narrativas e trajetórias "capturadas" na pesquisa, em conversas 'não jogadas fora”, pulsam memórias da cidade, quando se podia percorrer suas ruas a pé.

Os bares, os espaços da universidade, as praças e mesmo a casa de alguns dos atores entrevistados foram palco e processo de uma teia de relações. Neles se trocavam informações, debatiam-se ideias, conheciam-se pessoas, ampliava-se o acesso às novas produções culturais, como também às discussões e embates políticos. Com efeito, tais temas são indispensáveis para se compreender o ponto de partida de práticas, comportamentos, lugares e sociabilidades que forjaram um estilo de vida denominado, pelos atores pesquisados, como "boêmio".

A "boemia" é uma categoria nativa vinculada a universos distintos, mas em associação. A ela se relacionam alguns traços comuns, como modos de conduta, rotinas de ação, comportamentos, postura outsider diante de valores "conservadores", ou melhor, "caretas", e ideias de produção cultural numa perspectiva vanguardista. Politicamente, predominava um posicionamento dito "de esquerda", oposto à repressão ditatorial.

Bourdieu (2008, p. 164) discute os estilos de vida como "produtos sistemáticos dos habitus", ou seja, "sistemas de sinais socialmente qualificados" que definem distinções entre grupos e classes. Dessa forma, analisa o gosto como algo expresso na origem dos estilos de vida. Suas análises auxiliam a tecer um quadro analítico dos estilos de vida como formas de distinção. Nessa análise, o estilo de vida se expressa na ideia do gosto, do consumo cultural, das formas e maneiras de se comportar que diferem uma classe em função de suas práticas de consumo, modos de conduta e opções de escolha, ao tempo em que distingue o indivíduo de uma mesma classe. Quando Becker (2008) nos apresenta o estilo de vida dos músicos norte-americanos, na década de 1960, discute a categoria outsiders como pessoas ou grupos em desvio de regras. A sua abordagem caminha numa direção diferenciada de outras teorias a respeito do desvio. Desvio não como algo fora da "média", ou como uma anomalia ou "doença" social e mental, mas uma relação com as regras e a forma como são construídas e impostas a um grupo de pessoas. Regras e desvios variam de acordo com o grupo social aos quais são impostas. Assim, a posição de outsider pode variar sob a ótica de quem observa a regra e como os desvios a essa mesma regra são sentidos pelo grupo. Sua pesquisa sobre os músicos demonstra atividades consideradas legais, mas "sua cultura e o modo de vida são suficientemente extravagantes e não-convencionais para que eles sejam rotulados de outsiders pelos membros 
mais convencionais da comunidade" (idem, p. 89).

A condição de outsider, sob a lente teórica de Becker, perpassa os comportamentos desviantes, as posturas exageradas. Essa linha de abordagem é interessante para o entendimento dos atores sociais da "boemia", que adotam, em suas práticas, comportamentos e atitudes que buscam diferenciar-se do convencional, na forma de quebrar convenções, na maneira de produzir cultura, no estilo de ser esquerda, no jogo de cena de certas personagens, no uso de drogas (em alguns casos), no consumo etílico, adotando atitudes contra o oficial, o burocrático, o hierárquico, o autoritário, o careta. Ser outsider consistia numa maneira de se opor à visões hegemônicas institucionalizadas na família, no espaço público, na forma de ser vestir, nos gostos estéticos. Porém, o ser outsider colore-se de ambiguidade; não se era um outsider ou um boêmio e boêmia todo o tempo. O questionamento dos valores não eliminava a importância da família, do trabalho, da formação universitária, nem de ter um "canto" na cidade que fosse "familiar".

Essas perspectivas teóricas ajudam a compreender comportamentos e visões de mundo características dos grupos e segmentos que compuseram trajetórias, repertórios culturais e comportamentos que aqui compreendemos sob a ideia de estilo de vida boêmio, não como grupo hermético de pessoas em harmonia de pensamentos e ações, mas enquanto agrupamento que aderiu, em determinado momento de suas vidas, da história do país e da expansão urbana da cidade, a comportamentos não-convencionais imbricados com a música, a arte, a política e a cultura.

Sem esses elementos comuns, ver-se-ia apenas grupos de pessoas diferentes entre si que se encontravam na noite para beber e conversar nos bares de então, como hoje ocorre nos inúmeros lugares de bebida espalhados pela cidade. Diante do cerceamento das liberdades e sob a ebulição das mudanças de costumes, a juventude colocava-se, predominantemente, na linha de frente das atitudes de contestação e crítica social e política. Eis um elemento que permite a aglutinação de pessoas diversas que passavam a conviver nos espaços públicos dos bares e nas noites da cidade, forjando um modo de viver os espaços públicos da cidade.

Interessante destacar que as residências, as festas, as escolas, os cinemas, os clubes de bairros populares, como o Clube de Regatas da Barra do Ceará, e os da elite, como Náutico Atlético Clube, concentravam os principais lugares de sociabilidade até então, marcados por um convívio mais restrito, característico de uma cidade ainda com ares provincianos. Outros cantos havia, mas que eram quase exclusivos de um convívio masculino, para quem a rua e seus encantos e desencantos sempre foram cortinas abertas. Eram lugares de "má reputação" e de 
iniciações nas artes do amor, ou simplesmente cabarés, prostíbulos, zonas de meretrício, "casas de recursos", bares, chatôs, onde se encontravam, conforme termo pejorativo usado à época, as "mulheres públicas". Em geral, esses lugares "suspeitos" concentravam-se no centro da cidade, principalmente se suas personagens são pessoas ligadas ao "submundo social" ou aos segmentos mais populares.

A expansão urbana alarga as opções e espaços de lazer e de sociabilidades públicas. Surgem novos bares, com perfis que atraem um público mais outsider, como os bares Balão Vermelho ("Bar dos Comunistas", como era conhecido), no centro, o Cirandinha e o Restaurante Estoril, na Praia de Iracema, O Anísio, Bem, Benzinho, Copacabana, Nilo, Amor, Black \& White, Sereia, Gordo e o Magro e Rebouças, na Beira Mar ou ruas próximas à orla.

O bar assume importância também como espaço privilegiado de produção artística, trincheira política e dissipação, frente às ameaças impostas pela ditadura. Neles, encontram-se turmas de amigos, algumas das quais deram origem ao chamado "Pessoal do Ceará", formado, dentre outros, pela cantora Téti e os cantores e compositores Rodger Rogério, Petrúcio Maia, Fagner, Belchior e Ednardo. Nas palavras de um de meus interlocutores,

[...] e o Anísio (Bar do Anísio) é essa turma que depois foi rotulada de Pessoal do Ceará. Aquela turma ali, Ednardo, Fagner, Belchior, todos andavam, frequentavam muito por lá. Uma turma que foi se conhecendo nos festivais de música. Dos festivais, eles foram habitués de alguns bares, né. Um desses bares, o principal foi o Anísio. Embora o Estoril nunca tenha deixado de ser um desses lugares né (trecho de entrevista),

A leitura de jornais e de outros estudos sobre o período em foco conduziram-nos a algumas dessas personagens, dentre elas Rodger Rogério e Fausto $\mathrm{Nilo}^{7}$, ambos cantores e compositores cearenses, as quais guiaram-nos a outras, tais como Claudio Pereira ${ }^{8}$ e Augusto Pontes ${ }^{9}$ (ambos já falecidos), Ieda Ester-

\footnotetext{
7 Fausto Nilo é nascido na cidade de Quixeramobim (Sertão Central do Ceará), em 1944. Mudou-se para Fortaleza em 1955. Arquiteto, cantor, compositor, membro do Pessoal do Ceará, fez dos espaços da universidade sua casa por vários anos. Atualmente, é arquiteto reconhecido e cantor com vários discos gravados, sendo nacionalmente conhecido.

8 Claudio Pereira nasceu em 1945 em Fortaleza. Nos anos 1960 e 1970 participou e foi líder do movimento estudantil secundarista, nos anos 1960 e assumiu o papel de agitador cultural. Trabalhou no Banco do Nordeste do Brasil e exerceu atividade de jornalismo, formando-se em Direito. Foi por vários anos secretário de cultura do município de Fortaleza, quando fundou a FUNCET. Morreu em maio de 2010.

9 Augusto Pontes nasceu em 1935, em Fortaleza. Foi um dos líderes do movimento estudantil secundarista e um dos mobilizadores culturais nos anos 1960 e 1970. Estudou Filosofia e Publicidade, atuando como professor na UnB, publicitário e secretário de cultura após a abertura política. Foi um dos grandes incentivadores dos cantores que vieram a compor o Pessoal do Ceará. Morreu em 2009.
} 
gilda, Aldifax Rios, Francis Vale ${ }^{10}$, René Barreira ${ }^{11}$, para citar alguns. Importa-nos, contudo, mais que nomeá-las, entendê-las como um agrupamento social formado, em sua maioria, por jovens estudantes na época, que conviveram com personagens de outras gerações e contextos, vindo a integrar o estilo de vida boêmio. Logo, ainda que os jovens em início de suas descobertas estéticas, urbanas e sociais, fossem majoritários, integraram esse estilo de vida, intelectuais de esquerda, militantes políticos, "velhos boêmios", cantores e "cantoras da noite" e "mulheres liberadas".

\section{BARES, “BOEMIA" E ESTILO DE VIDA}

Segundo desafia Pais, "a cidade não é apenas um lugar para habitar, é também um lugar para imaginar” (PAIS, 2010, p.79). Sonhos, canções, juventude, crítica de costumes de jovens moradores habitam também a cidade de Fortaleza. Seus locais de encontro são descobertos em "rondas boêmias", perambulando, flanando por ruas, esquinas, becos e pela praia. Ganhava-se a rua, fazia-se dela um palco, não como mero cenário, mas como sentido de um existir fora de espaços privados e construir intimidades.

O sentido público das ruas é uma construção da modernidade (BENJAMIN, 1989). Antes, os espaços de sociabilidade circunscreviam-se à privacidade de lares e aos lugares de oração. Pais (2007) elabora uma curiosa pesquisa sobre as "artes de amar da burguesia" em Portugal dos Séculos XVIII e XIX. Nela nos aponta as estratégias de sedução nos espaços privados e públicos, quando eram os movimentos do corpo que falavam, já que a proximidade física era impedida pela rígida moral dos costumes da época. Quando a sociabilidade passa a ter nas ruas seu espaço por excelência, os jogos de interação pautam-se nas formas que a etiqueta social definia como regras de convívio e a sociabilidade adquire ares de formalidade. O corpo denota uma linguagem como um "discurso convencionalizado", já nos prevenia Goffman sobre o comportamento em lugares públicos (GOFFMAN, 2010, p. 45).

O convívio nos espaços públicos é revelador para se pensar as formas de

10 Francis Vale nasceu em 1945 no Pará, mas mudou-se para Fortaleza aos quatro anos de idade. Na época em foco era estudante do curso de Direito da UFC, mas sempre com um grande interesse pelo cinema. Participou de todas as atividades e grupos culturais do movimento estudantil e era membro do Centros Populares de Cultura - CPC. Morreu em 2017.

11 René Barreira, à época estudante de Ciências Sociais, nasceu em 1945, em Jaguaribe, vindo morar com a família em Fortaleza aos sete anos de idade. Foi militante da AP - Ação Popular, ligada à JEC - Juventude Estudantil Católica, sendo presidente da UEE, União Estadual dos Estudantes, em 1962. Esteve preso por um mês em 1965 por ocasião de um congresso da UNE em São Paulo. Foi reitor da UFC e Secretário de Ciência e Tecnologia do Ceará. 
sociabilidade estabelecidas nas cidades. Sobre isso, Sennet (1988) discute Paris e Londres, no Século XVIII, duas cidades símbolos da modernidade. De acordo com o autor, nessas cidades os cafés eram um dos espaços de sociabilidade por excelência, um ponto de encontro, e neles se exercia uma prática de discurso diferenciada. Lá, havia uma suspensão temporária das distinções de estrato social para garantir um fluxo livre da conversa. E essa conversa tinha características próprias, ou seja, os discursos dos cafés versavam sobre temas gerais sobre os quais qualquer pessoa poderia opinar. Diz o autor: "qualquer pessoa que estivesse sentada num café tinha o direito de conversar com quem quer que fosse, abordar qualquer assunto, quer conhecesse as outras pessoas, quer não, quer fosse instada a falar, quer não. Era desaconselhável fazer referências às origens sociais das pessoas com quem se fala no café, porque isso poderia ser obstáculo ao livre fluxo da conversa" (Idem, p. 109).

Esses espaços são, segundo o autor, instituições romanceadas e idealizadas, como lugares nos quais havia uma "conversa alegre e civilizada, bonomia e amizade estreitas em torno de uma xícara de café, enquanto é ainda desconhecido o silêncio das casas de gim" (ibidem, p. 108). Eram espaços de informação mais importantes das grandes cidades. Um tipo de sociabilidade oposto ao que se vivenciava nos clubes de homens: círculo restrito e exclusivo, importância a quem fala e não ao que se fala. Nos cafés predominavam "conversas sem rosto". O lazer surge pela liberação da rigidez da vida das pequenas cidades e dos deveres de sobrevivência. "A sociabilidade é fruto do lazer" (ibidem, p. 150).

Abordagem semelhante realiza Simmel (2006) sobre a sociabilidade. Para ele, sociabilidade define-se como uma forma lúdica ou pura da sociação, ou seja, o desejo e a satisfação de estar junto, a interação como um fim em si mesmo. Na análise simmeliana, a conversa é compreendida como uma das formas puras de sociabilidade. Não aquela cujo tema é o objetivo central, mas a conversa cujo tema é um mero pretexto para a interação, um "jogar conversa fora”, como a "conversa sem rosto" de Sennet.

Logo, a sociabilidade implica sensações e sentimentos gerados na interação. Os interesses individuais guiam as ações e interações, mas o indivíduo não é completamente autônomo, ainda que não seja uma mera vítima das circunstâncias sociais. Na sociabilidade, o jogo e a arte são princípios fundantes. Joga-se como se todos fossem iguais. Nesse jogo, distância e proximidade se fazem presentes. Distância observada na reserva e cortesia com a qual interagimos, que nos protegem e nos possibilitam conviver com mais liberdade, sem a prisão das relações pautadas na cerimônia, nem a proximidade sufocante que limita a indi- 
vidualidade. Daí o prazer que proporciona na sociabilidade dos bares a ideia de que se pode dizer tudo porque "é coisa de bar", ou seja, não se deve levar tão a sério, assim como não se leva a sério a "filosofia de bar".

A importância dos bares como espaços de sociabilidade da cidade não nasce, certamente, com o que aqui se relaciona à boemia, nem tampouco nos anos 60 e 70 do século passado ${ }^{12}$. Contudo, nessas décadas ampliam-se em número e ocupam novos espaços de lazer, como a orla marítima da cidade, passando a ser frequentados por grupos de estudantes, músicos, artistas, jornalistas, políticos ou simples apreciadores da arte de "jogar conversa fora". Tornam-se espaços por excelência da prática e de atitudes transgressoras, da produção de músicas, de projetos e sonhos. Mais que isso, passam a ser espaço da sociabilidade feminina, e as vozes de mulheres se fazem ouvir nos bares eleitos por grupos de intelectuais e artistas nas noites de Fortaleza.

Constituía-se uma "flanerie" (BENJAMIN, 2007) que definia uma cartografia e um jeito de ser. Tal maneira de ser não corresponde à individualidade apenas, mas condiz com rotinas de ação de grupos e categorias sociais. Cabiam as atitudes que contradiziam as normas, frequentar bares e restaurantes cuja característica principal não fosse a assepsia, a "boa frequência" de pessoas "de família”, mas aqueles onde se podia estar em liberdade, com um violão, uma roda de amigos (as), as (os) namoradas (os) e amigas (os).

Um desses bares chamava-se O Anísio, que se localizava na orla marítima da cidade. Lugar modesto, sem qualquer requinte, lá se podia comer um peixe-frito, pescado pelo próprio Anísio. Esse bar reunia grupos de amigos em torno da música, da conversa e de comportamentos ditos "liberais". No Anísio se podia tomar uma "bebida honesta", com valores acessíveis a estudantes. Lá, as mulheres podiam assumir posturas mais ousadas no modo de falar e vestir, sem se preocupar com olhares perscrutadores.

As "rodas boêmias" agregam-se sob vários pretextos - a música, o esporte, a política, a literatura. A arte de argumentar, de não perder a piada, é um dos elementos que as compõem. Nesse quesito, Augusto Pontes ${ }^{13}$ é uma personagem icônica na memória de seus amigos e companheiros de mesa. Falecido no ano

12 No Século XIX Fortaleza havia experimentado outras experiências associadas à boemia intelectualizada e irreverente, cujo marco foi a Padaria Espiritual, movimento literário da "boemia literária e etílica de Fortaleza”, parafraseando Ponte (In Souza, 2002). No contexto em tela, a repressão e o clima de tensão impostos pela ditadura conferem aos bares e espaços de lazer relevância nas trocas e formas de sociabilidade de determinados segmentos da cidade.

13 Jornalista, publicitário, produtor cultural, "agitador cultural”, Augusto Pontes foi uma das personagens mais citadas em todas as conversas com meus interlocutores, como um dos ícones dessa boemia fortalezense do período em estudo. 
de 2009, algumas frases atribuídas a Augusto Pontes são repetidas por todos os meus interlocutores. Frases do tipo "Há bares que vem para o bem"; "Agite, agite, mas me traga o jipe, porque passeata eu não vou a pé, Mao Tse"; "A união só se faz à força"; "Quanto mais a mesa cresce, mais a cultura desaparece", que denotam uma crítica ácida a algumas práticas e ideais da esquerda considerada mais radical.

Nesse contexto, as noitadas varavam madrugadas. Um bar seguia-se a outro, até, finalmente, chegar ao "bar fim de noite", aonde se ia "forrar o estômago", ou simplesmente tomar um caldo para seguir para casa. Importava "ruar", sair pela cidade a pé ou nos poucos carros existentes nas "rodas boêmias". A cidade favorecia a vida noturna e a descoberta da orla marítima ampliava as opções de lazer, bem como o caráter lúdico desse tipo de sociabilidade.

Outros componentes desse universo são o saber falar e ouvir ao estar numa mesa de bar. Algo como uma etiqueta "boêmia" para a qual saber calar quando alguém canta, compreender a jocosidade e os assuntos, demonstrar criticidade, sensibilidade e irreverência são valorizados como práticas que distinguem. Esses são aspectos destacados nas entrevistas e que denotam não apenas formas de conduta e convívio, mas elementos que compõem representações sociais construídas por esses sujeitos, sobre si e sobre os demais, nas suas deambulações e usos da cidade.

Os bares eram redutos do que se passou a denominar, na época, de "esquerda festiva" ${ }^{\prime \prime}$, uma esquerda que se assemelhava ao que Benjamin (2007) denominava "conspiradores profissionais". Entretanto, a "esquerda festiva" criticava a postura mais sisuda da "esquerda partidária", ainda que muitos de seus membros fossem filiados a partidos políticos, sobretudo ao PCB - Partido Comunista Brasileiro, então na clandestinidade.

Em Fortaleza, a expressão "esquerda festiva" se soma a outros termos como diferenciadores. Os culturais", a "culturalha", a "patota divina", "os eleitos", "os cabeças" foram algumas denominações utilizadas durante as entrevistas e nas leituras de livros e jornais sobre a época para se referir a tal agrupamento social,

\footnotetext{
14 A expressão "esquerda festiva" foi forjada na cidade do Rio de Janeiro, e aparece no livro do escritor Zuenir Ventura, "1968- o ano que não acabou", como sendo de autoria do colunista Carlos Leonam, que, em 1963, utilizara o termo para se referir a um tipo de esquerda mais condizente com o comportamento do carioca. Leonam sugeriu a expressão "esquerda festiva" para qualificar a esquerda brasileira. Desde então, tal expressão passou a designar a esquerda que frequentava bares, botequins e festas e discutia política. $\mathrm{Na}$ obra de Callado (2001), "Bar Don Juan", o termo aparece para se referir aos boêmios, artistas e intelectuais que se reuniam no bar com a intenção de discutir política, cultura e questões existenciais, alguns dos quais com projetos de "fazer a revolução" no país a partir das guerrilhas, influenciados pela Revolução Cubana e pelos ideais socialistas.
} 
diferenciando-o de outras condutas e modos de $\operatorname{ser}^{15}$. Essas expressões definiam, ou tentavam definir, indivíduos que não se identificavam com a esquerda convencional e optaram por vivenciar uma reação à ditadura fincada no humor e nos encontros em bares, restaurantes, espaços acadêmicos, com o intuito de cantar, conversar, discutir e dividir angústias, como uma resistência cultural que, em alguns momentos, rivalizava politicamente com as formas mais radicais de resistência.

Nesse universo, uma frase do publicitário Augusto Pontes incorporava, de maneira crítica e com certo conteúdo de humor, uma forma de representação que se criou em torno desse agrupamento: "Não quero ovo com cultural novo". Sempre que chegava uma pessoa novata à mesa onde estivesse Augusto, com intenções de se integrar ao papo e à discussão, ele repetia a frase, de maneira a deixar o suposto ou potencial integrante desconcertado. O "cultural novo" remete ao fato de que havia outros "culturais" e que essa terminologia era incorporada nas narrativas que se construíam em torno dos sujeitos integrantes desse estilo de vida. Era também uma forma de construir marcadores de diferença ou distinção, entre as várias turmas e grupos que frequentavam os bares.

Estar no bar é para os interlocutores "saber beber". O consumo etílico exibe contradições e distinções sociais, como entre "boêmio" e "alcoólatra", por exemplo. Falamos em consumo no sentido amplo, não apenas compra de mercadorias, mas como estilos de vida que caracterizam formas de distinção social. Observa-se, nessa tentativa de estabelecer distinção frente ao "alcoólatra", uma zona de fronteira, ou seja, o "boêmio não é alcoólatra", como também "não é alienado político". Nesse sentido, recuperando a discussão de Oliveira (1976) sobre a "identidade contrastiva", percebe-se a formulação de oposições, de fronteiras, para estabelecer marcações e identificações com aspectos mais positivos e valorizados em torno do "ato de beber". Não ser alcoólatra implica, para meus interlocutores, uma relação com a bebida pautada por certa etiqueta "boêmia". Beber por beber configurava atitudes dos que não comungavam da "boa boemia".

Outro aspecto observado diz respeito à frequência ao bar. Ir ao bar, para meus interlocutores, é tão importante quanto qualquer compromisso social. E esse estar no bar não se confunde com a prática de ir, sentar, beber, pagar a conta e partir. Estar no bar denota uma "rotina de ação", termo utilizado por White (2005) para definir as práticas rotineiras das gangues de Corneville em seu estudo sobre as gangues de esquina da Boston dos anos 1940. No contexto por nós estudado, o bar assume o sentido de extensão do lar, um canto no qual se criam 
vínculos e se estabelecem relações de identidade e amizade ${ }^{16}$. Estar lá implica ser reconhecido como um "habitué", conhecer e ser reconhecido, não um "indivíduo qualquer”, mas uma pessoa, no sentido de Da Matta (1997), ou seja, não se é um "numeral morador"17.

Afora isso, o uso do humor agregava uma coloração de crítica ácida, um "humor negro", cujo ponto máximo é o trocadilho, a demonstração de inteligência, o pensamento ágil. Nas mesas dos bares a palavra, além da música, ganhava importância nos debates e confrontos de ideias e posições. Dessa forma, a inserção em determinadas "rodas" não se dava simplesmente, e algumas pessoas que tentaram ser partícipes não conseguiram seu ingresso por não terem "sintonia nas conversas", isto é, não compartilharem o repertório comum, não adotarem um comportamento menos atrelado à moralidade considerada "careta". Isso não implica dizer que havia uma homogeneidade entre os frequentadores. Sobre isso, a definição de Bourdieu é primorosa,

O bar não é apenas o local em que se vai beber, mas para beber em companhia e em que é possível instaurar relações de familiaridade baseadas na suspensão das censuras, convenções e conveniências que devem ser respeitadas nas trocas com estranhos (BOURDIEU, 2008, p. 173)

A "arte de zombar dos outros sem irritá-los" (Bourdieu, idem) condiz com atitudes menos rígidas, sobretudo quando o enfoque recai sobre as mulheres, cujo ingresso no mundo da noite, na vida pública de bares e boates é inaugural. As mulheres, não mais vinculadas à prática da prostituição, passam a compor a cena boêmia da cidade a partir da década de 1960. A fala a seguir denota uma rica cena num dos bares frequentados pelas personagens boêmias da cidade, sob enfoque da pesquisa,

Ela simplesmente levantou a blusa mesmo, no meio de todo mundo, tirou o sutiã e entregou pro garçom. Nesse dia eu só faltei morrer de rir! (risos) Sabe o que é você rir, rir, rir de se sentar no chão de rir? Porque o garçom chegou muito contrariado pra Betina, minha amiga que me ajudava no caixa, "olha aí, Betina, a cliente disse que vai deixar aqui como

16 Cabe destacar que os bares, ainda que espaços liminares, não estão completamente livres da censura, da repressão e mesmo dos conflitos e tensões. No bar Balão Vermelho, para citar um exemplo, alguns dos atores pesquisados foram presos pelos militares. Era comum haver "batidas", sobretudo pela imagem que esses espaços detinham nos aparelhos de repressão como "redutos de comunistas". O clima de descontração não eliminava, de todo, as tensões do contexto político, dando origem a divergências e desentendimentos irrigados pelo álcool.

17 Poema "A Casa sem Raiz", de Carlos Drummond de Andrade 
garantia da conta dela!", com o sutiã pendurado na mão. Eu achei assim ótimo essa história. Uma coisa dessa eu até dispensaria essa conta que ficou pendurada, e eu acho que ela terminou nem pagando mesmo viu. Uma atitude desse tipo é absolutamente revolucionária! Uma mulher, num bar, levantar a blusa, tirar o sutiã e entregar pro garçom, como garantia de uma conta que ela não podia pagar! (Natércia Benevides18 - entrevista)

A relação da mulher com a noite e com os espaços ditos boêmios não segue caminhos idênticos aos dos homens. Por longos anos, a única mulher a ter legitimidade para frequentar os ambientes noturnos era a prostituta. As mulheres das classes médias e abastadas estavam circunscritas ao espaço doméstico, familiar e de atividades de lazer diurno. O espaço da rua era da trabalhadora e das prostitutas, também em atividade de trabalho e subsistência. Ao longo dos anos e das mudanças vivenciadas, esse espaço da rua se diversifica com o ingresso de mais mulheres no mercado de trabalho, de novas atividades de lazer e sociabilidade.

A vida de "mulheres liberadas", conforme se definem minhas interlocutoras, rompe com essa imagem do feminino. Decidiram "ruar", "sair" e "boemar", verbos que afloram como flores no jardim, ao ouvi-las falar sobre sua juventude. Foram chamadas "mulheres liberadas" por sua iniciativa de sair desacompanhadas e não ter de pedir permissão; de estar nas noites, nos bares, nas ruas da cidade, nas mesas de discussão, de risadas, de namoros e de amizades; pagar suas próprias contas e definir seus passos e formas de caminhar.

Maior participação das mulheres, repertório de frases de efeito, relação com a bebida, produção cultural, música, bares como espaços de interação são alguns dos marcadores do que aqui tratamos como "estilo de vida boêmio". Essa apropriação cultural do espaço público apresenta a face de um colorido político-utópico expresso na palavra "revolução". Revolução política para uns, revolução dos costumes, da sexualidade para outros. O espaço público, no qual se soltavam gestos, versos e opiniões, é a oportunidade de exercitar o que Habermas denomina "a arte do raciocínio público". A conversa na rua, nas praças e, sobretudo, nos bares, fomenta ideais, projetos políticos e artísticos, exercita a discussão sobre o país e a cidade.

18 Natércia é nascida em Rondônia, em 1948, e veio para Fortaleza com sete anos de idade. Violonista, cantora, funcionária pública, "cantora da noite" na época da pesquisa. 


\section{CONSIDERAÇÕES FINAIS}

Nosso percurso, aqui traçado, conduziu-nos ao princípio do processo de metropolização e para um modo ou estilo de viver dentre tantos outros. Afinal, aqui traçamos um recorte de um perfil e um modo de vida relacionado com a chamada "boemia" de uma classe média intelectualizada, num determinado momento da cidade. Dissemos que o "universo boêmio" não se restringe a esse recorte espaço-temporal, tampouco às personagens e classe social enfocadas. Apenas que com esse recorte teórico-metodológico podemos compreender a emergência de um estilo de vida que é também um estilo de viver a cidade, numa fase de transição e num contexto histórico específico.

Cidade e estilos de vida, Fortaleza e boemia, proximidade e distância, liberdade e repressão, cultura e política, casa e rua. Termos que não são meros jogos de palavras, mas que se imbricam no entendimento da realidade humana, social e política de um contexto específico que buscamos analisar na tentativa de compreender as finas teias de relações que proporcionaram a emergência de estilos de vida ou estilo de vida designado boemia, na cidade de Fortaleza, entre as décadas de 1960 e 1970. Boemia que não emerge como categoria teórica, mas nativa, utilizada por atores sociais oriundos de uma classe média de Fortaleza, num momento em que a cidade passava por transformações profundas de suas feições urbanas e de seus modos de vida, para qualificar e dar sentido, para esse agrupamento social específico, aos seus comportamentos, suas formas de lidar com a noite, seus espaços de lazer e encontro, suas visões de mundo e produções culturais.

Os bares congregam uma heterogeneidade de pessoas, as quais, em comum tinham um espaço de sociabilidade, certo repertório cultural, uma atitude de crítica e contestação aos rigores da ditadura e aos valores tidos como conservadores e uma imbricação com os campos artístico e cultural da cidade. Os "cantos" da noite deixam de ser exclusivamente masculinos e novas mulheres entram em cena. Não mais apenas as prostitutas estão nas noites, nos bares, no consumo etílico, no sexo sem casamento. São mulheres que vinham da classe média, da universidade, que passam a dividir mesas, contas e trajetórias de vida no espaço público.

Por fim, compreendemos um estilo de vida, nomeado boêmio, como uma possibilidade de vivência com a cidade, com seus bares, espaços públicos. Determinadas cristalizações e romantizações necessitam ser colocadas no seu substrato social e humano, no seu tempo e lugar, de forma a compreendermos as finas redes que se tecem nos cantos da cidade. Entre copos, conversas e canções, uma 
possibilidade de viver a cidade, quando, como diz a canção "Pé de sonhos"19, os sonhos brotavam nos jardins.

\section{REFERÊNCIAS}

BACHELARD, Gaston. A Poética do Espaço. $2^{\mathrm{a}}$ edição. São Paulo: Martins Fontes, 2008.

BECKER, Howard S. Outsiders. Estudos de sociologia do desvio. Rio de Janeiro: Zahar Editora, 2008.

BENJAMIN, Walter. Passagens. Belo Horizonte: Editora UFMG; São Paulo: Imprensa Oficial do Estado de São Paulo, 2007.

BENJAMIN, Walter. Charles Baudelaire. Um lírico no auge do Capitalismo. São Paulo: Brasiliense, 1989

BIERNACKI, Patrick; WALDORF, Dan. Snowball Sampling. Problems and Techiniques of Chain Referral Sampling. In Sociological Methods \& Research. V. 10, N02, November, 1981.

BOURDIEU, Pierre. A Distinção. Crítica social do julgamento. São Paulo: EDUSP; Porto Alegre: Zouk, 2008.

BOURDIEU, Pierre. As Regras da Arte. Gênese e estrutura do campo literário. São Paulo: Cia das Letras, 1996.

CALlADO, Antonio. Bar Don Juan. 8a edição. Rio de Janeiro: Nova Fronteira, 2001.

CANCLINI, Néstor García. Consumidores e Cidadãos. Conflitos multiculturais da globalização. 4 a edição. Rio de Janeiro: Editora UFRJ, 1999.

CANCLINI, Néstor García. Culturas Híbridas. Estratégias para entrar e sair da modernidade. São Paulo: EdUsp, 2008.

CASTRO, Ruy. Chega de Saudade. A história e as histórias da Bossa Nova. São Paulo: Cia das Letras, 2008.

CHALHOUB, Sidney. Trabalho, Lar e Botequim. O cotidiano dos trabalhadores no Rio de Janeiro da belle époque. $2^{\mathrm{a}}$ edição. Campinas, SP: Editora da UNICAMP, 2001.

19 Pé de sonhos, composição de Antonio José Soares Brandão e Petrúcio Maia, compositores cearenses integrantes do contexto tratado no texto. 
DA MATTA, Roberto. A Casa \& a Rua. Espaço, cidadania, mulher e morte no Brasil. 5a edição. Rio de Janeiro: Rocco, 1997.

DARNTON, Robert. Boemia Literária e Revolução: o submundo das letras no Antigo Regime. São Paulo: Cia das Letras, 1987.

GOFFMAN, Erving. Comportamento em Lugares Públicos. Petrópolis: Vozes, 2010.

HABERMAS, J. Mudança estrutural da esfera pública. Investigações sobre uma categoria da sociedade burguesa. São Paulo: Unesp, 1990

LEITÃO, Juarez. Sábado, estação de viver: histórias da boemia cearense. Fortaleza: Editora Premius, 2000

LEITE, Rogério Proença. Espaços públicos na pós-modernidade. In FORTUNA, C. \& LEITE, R. P (Orgs.) Plural de Cidade: novos léxicos urbanos. Coimbra: Ed. Almedina, 2009.

MADUREIRA, Sevy. Bairro do Recife. Porto seguro da boemia. Recife: Prefeitura da Cidade do Recife, SEPLAN, 1995.

MAGNANI, José Guilherme Cantor. Quando o campo é cidade: fazendo Antropologia na Metrópole. In MNANI, J. G. C. \& TORRES, L. L. (org.). Na Metrópole: textos de Antropologia Urbana. São Paulo: EdUsp, 1996.

MARQUES, Roberto. Contracultura, tradição e oralidade: (re)inventando o sertão nordestino na década de 70. Trajetos, revista de História. Fortaleza: UFC, v. 3, n. 6,2005

MATOS, Maria Izilda Santos de; FARIA, Fernando A. Melodia e Sintonia em Lupicínio Rodrigues. O feminino, o masculino e suas relações. Rio de Janeiro: Bertrand Brasil, 1996.

MUSSE, Christina Ferraz. Imprensa, cultura e imaginário urbano: exercício de memória sobre os anos 1960/70 em Juiz de Fora. Tese de doutoramento. Programa de Pós-graduação em Comunicação da Escola de Comunicação da UFRJ. Rio de Janeiro, 2006.

OLIVEIRA, Roberto Cardoso de. Identidade, etnia e estrutura social. São Paulo: Pioneira, 1976.

PAIS, José Machado. A Prostituição e a Lisboa Boêmia. Do século XIX a inícios do século XX. Porto: Ambar, 2008.

PAIS, José Machado. Artes de Amar da Burguesia. 2a edição. Lisboa: ICS, 2007.

PAIS, José Machado. Lufa-Lufa Quotidiana. Ensaios sobre cidade, cultura e vida urbana. Lisboa: ICS, 2010. 
PIMENTEL, Mary. Terral dos Sonhos. O cearense na música popular brasileira. Fortaleza: Secretaria de Cultura do Estado do Ceará, 1994.

RAFAEL, Ulisses. Sociedade do delírio: Boemia e literatura portuguesa no século XIX. In Oficina do Centro de Estudos Sociais da Universidade de Coimbra, $\mathrm{n}^{\circ}$ 341, 2010. Disponível em www.ces.uc.pt/publicacoes/oficina/ficheiros/341.pdf.

RAGO, Margareth. Do Cabaré ao Lar. A utopia da cidade disciplinar. Brasil 18901930. 3a edição. Rio de Janeiro: Paz e Terra, 1997.

ROGÉRIO, Pedro. Pessoal do Ceará: hábitus e campo musical na década de 1970. Fortaleza: Edições UFC, 2008.

SEIGEL, Jerrold. Paris Boêmia. Cultura, política e os limites da vida burguesa (1830-1930). Porto Alegre: L \& PM, 1992.

SENNET, Richard. Carne e Pedra. O corpo e a cidade na civilização ocidental. $4^{\text {a }}$ edição. Rio de Janeiro. São Paulo: Editora Record, 2006.

SENNET, Richard. O Declínio do Homem Público. As tiranias da intimidade. $4^{\mathrm{a}}$ reimpressão. São Paulo: Companhia das Letras, 1988.

SILVA, Daniele Costa da. Entre copos, conversas e canções: um estilo "boêmio" de viver a cidade. Tese de doutoramento em Sociologia. Fortaleza: UFC, 2012.

SILVA, Luiz Antonio Machado da. O significado do Botequim. In: HOGAN, Daniel J. et al. Cidade: usos \& abusos. São Paulo: Brasiliense, 1978.

SIMMEL, Georg (b). Questões Fundamentais de Sociologia. Rio de Janeiro: Jorge Zahar, 2006.

SIMMEL, Georg. A Metrópole a Vida do Espírito. In FORTUNA, Carlos (org). Cidade, cultura e globalização. Oeiras: Celta, 2001.

WHITE, William Foote. Sociedade de Esquina. A estrutura social de uma área urbana pobre e degradada. Rio de Janeiro: Jorge Zahar, 2005.

\section{INTERSECTIONS BETWEEN CULTURE, ART AND POLITICS IN THE "BOHEMIAN" FORTALEZA IN A DICTATORIAL CONTEXT}

\footnotetext{
Abstract: The focus of the article is the practices, environments and sociabilities of an urban lifestyle associated with the term "bohemian", in the city of Fortaleza between the decades of 1960s and 1970s, when artistic, political and intel-
} 
lectual groups delineate movements in the public space of the city, composing trajectories, identities and memories in a time-space demarcated by the dictatorial contexto. A "bohemian" in this sense, is used by these groups to define their practices and experiences in the urban space, under the repressive context lived in the country. They are characters who rehearse, in their wanderings, a lifestyle, acting with a grammar of senses and actions, while forging ideas, behaviors and practices of a new urban culture in a city that began to aspire to metropolitan air. The text is the result of the doctoral thesis in sociology, completed in 2012, which addressed this lifestyle in the city of Fortaleza, between the years 1960s and 1970s. The research was based on twelve interviews with some social actors participating in this context, as well as surveys in newspapers, books, music and documents of the context under analysis.

Keywords: City; Bohemia; Sociability; Lifestyle; Dictatorship.

\title{
INTERSECCIONES ENTRE CULTURA, ARTE Y POLITICA EN LA “BOHEMIA" DE FORTALEZA EN EL CONTEXTO DICTATORIAL
}

\begin{abstract}
Resumen: El foco del artículo son las prácticas, ambientes y sociabilidades de un estilo de vida urbano asociado al término "bohemia", en la ciudad de Fortaleza entre las décadas de 1960 y 1970, cuando grupos artísticos, políticos e intelectuales delinearon movimientos en el espacio público de la ciudad, componiendo trayectorias, identidades y memorias en un tempo y en um espacio demarcado por el contexto dictatorial. La palabra"Bohemia"en este sentido, es utilizada por estos grupos para definir sus prácticas y vivencias en el espacio urbano, bajo el contexto represivo vivido en el país. Son personajes que ensayan, en sus deambulaciones, un estilo de vida, actuando con una gramática de sentidos y acciones, al tiempo que forjan ideas, comportamientos y prácticas de una nueva cultura urbana en una ciudad que comenzaba a aspirar aires metropolitanos. El texto es resultado de la tesis del doctorado en sociología, concluida en 2012, que abordó ese estilo de vida en la ciudad de Fortaleza, entre los años 1960 y 1970. La investigación se basó en doce entrevistas con algunos actores sociales participantes de ese contexto, así como artículos periodísticos, libros, música y documentos del contexto en análisis.
\end{abstract}

Palabras claves: Ciudad; Bohemia; Sociabilidad; Estilo de vida; Dictadura. 